Aroueología Y SociedAD

№ $25,2012: 391-414$

ISSN: 0254-8062

RECIBIDO: SETIEMBRE DE 2012 ACEPTADO: OCTUBRE DE 2012

\title{
LA SIMBOLOGÍA DE LOS COLORES EN EL ARTE COPTO
}

\author{
Dr. Mohamed Ahmed Radí Abouarab \\ UNIVERSIDAD DE KAFRELSHEIKH, EGIPTO \\ mabouarab@art.kfs.edu.eg
}

\section{RESUMEN}

Los colores representan un simbolismo variado: la simbología cósmica, la biológica, la fisiológica, la psicológica, o la nacional-estética. Los colores poseen los mismos símbolos y significados en la cultura de los distintos pueblos antiguos, es una coincidencia que lleva una lengua común universal que se relaciona íntimamente con la religión.

La coincidencia de los símbolos de los colores sorprendió a los científicos e investigadores, de la cual sacaron una conclusión esencial: la unidad de las religiones en su esencia humana; la gran prueba consiste en el significado y simbología de los colores, que es el mismo para todos los pueblos y épocas. Analizamos el uso de los colores en el Arte Copto y cómo estos transmiten el mensaje religioso cristiano.

Palabras Clave: Símbolo, color, Copto, arte, Egipto.

\section{Abstract}

The colors represent varied symbolism: cosmic symbolism, biological, physiological, psychological, or national-aesthetic. The colors and symbols have the same meanings in the culture of the various ancient peoples, coincidentally carries a universal common language that is closely related to religion.

The coincidence of the symbols of the colors surprised scientists and researchers, which removed a key conclusion: the unity of religions in their human essence, the big test is the meaning and symbolism of the colors, which is the same for all peoples and all times. We analyze the use of color in Coptic art and how they transmit the Christian religious message.

KEYwords: Symbols, color, coptic art, Egypt. 


\section{INTRODUCCIÓN}

El color llamó la atención del hombre primitivo después de padecer daltonismo. El color que le llamó más la atención era el blanco; después, el verde; luego, consiguió ver el contraste completo entre el negro y el blanco. Posteriormente, de esta fase prehistórica, el hombre se fijó en el juego de los colores hasta que en algunas religiones antiguas consideraban los colores un símbolo sagrado, pues el blanco era el color de la castidad y pureza, el negro era el símbolo de la tristeza y la muerte, el azul para la fidelidad y lealtad, el amarillo de la malicia y envidia, el rojo símbolo de la violencia, y el verde el color de la esperanza. De los colores del arco iris, el hombre percibió siete colores como señal de buena suerte y el buen augurio. Lo más nuevo en la ciencia de los colores, o iconolingüítica y cromatología simbólica, es relacionar estrechamente entre el color y su símbolo, a base de la entidad del color y el interés de los pueblos por estos colores. Nos centraremos en la simbología e iconolingüística del color relativos al mensaje religioso.

Los colores van acompañando la evolución de la ciencia, ya que se puede ver la importancia de los colores en las industrias donde se encuentra un conjunto de colores que posee, en su uso popular, una elocuencia común entre la gente.

Muchos consideran que el color es el más bello e importante de los fenómenos de la naturaleza, es uno de los elementos que forman la imagen literaria por lo que contiene de significados artísticos, religiosos, psicológicos, sociales simbólicos y míticos. Los colores representan también un simbolismo variado, como la simbología cósmica, la biológica, la fisiológica, la psicológica, o la nacional-estética. Así mismo se ve que los colores tienen capacidad de causar efecto psicológico en el ser humano puesto que tiene la posibilidad de revelar su carácter; a qué color se asocia con conceptos específicos y posee significados especiales.

Probablemente el color es el elemento que más sufrió negligencia por parte de los científicos e investigadores, pero más curioso todavía es su estudio en la arqueología. Pues, como ocurre con los números, los colores poseen la misma simbología y significados en la cultura de los distintos pueblos antiguos, es una coincidencia que lleva una lengua común universal, que se relaciona íntimamente con la religión; dicha lengua es coherente con la realidad religiosa en general ${ }^{1}$. Asimismo los colores desempeñaron un papel principal en las artes de los pueblos antiguos, las diversas religiones vieron que el color es un símbolo sagrado. Los egipcios, por ejemplo, vistieron a Isis con ropa que brillaba con muchos colores, y en el Antiguo Testamento, Dios dijo a Noé: «Será el arco Iris mi pacto con la tierra». De ahí nació la idea de las Bellas Artes, de la idea religiosa; el objetivo de los colores, aparte de su simbología, era decorar los templos, los santuarios, y todo lo sagrado con estos bellos y bonitos colores. Pues cada color, en cualquier dibujo, representa una idea religiosa, por lo tanto éste obtiene su importancia como primera forma para expresar estas ideas y transmitirlas.

El cristianismo dio al lenguaje de los colores una nueva salida, les devolvió sus significados básicos olvidados, y se centró en sus dimensiones y símbolos principales, cuando se decoraron las catedrales con las brillantes escenas parietales, y las ventanas se vistieron con vitrales relucientes*.

De un pueblo a otro, de un credo a otro, de una civilización a otra, y de una religión a otra, el color volvió a ser un símbolo sagrado en la lengua popular, pues, todavía el azul es símbolo de fidelidad, el amarillo de la envidia, el rojo de la violencia, el blanco de la pureza, el negro de la tristeza y la muerte, mientras el verde es de la esperanza. Curiosamente, todavía la simbología de los colores es viva en

1 Baines, J. «Color Terminology and Color Classification: Ancient Egyptian Color Terminology and Polychromy». En: American Anthropologist, New Series 87, 1985, 2: 282-297.

* La religion islámica también tuvo la misma tendencia, se menciona en el Corán: «todo lo que para vosotros ha producido en la tierra con distintos colores» (Nasr, S.H. 2010. Qur'an. Encyclopædia Britannica [en línea]. <http://www.britannica.com/EBchecked/topic/487666/Quran>. El Corán Sagrado, Sura de la Abeja (16): 13), coniciden los colores con sus sombras en el mundo de los espiritus. 
las religiones monoteístas, lo que asegura su noble origen. En el cristianismo, se ven iconos y cuadros parietales donde San Juan viste de verde, Cristo y la Virgen, con vestimenta de color rojo o azul, mientras la representación de Dios, viste de blanco**.

La coincidencia de los símbolos de los colores sorprendió a los científicos e investigadores, de la cual sacaron una conclusión esencial, que es la unidad de las religiones en su esencia humana; la gran prueba de este caso consiste en el significado, y simbología de los colores, que es el mismo para todos los pueblos y en todas las épocas. Esta unidad religiosa genera unidad en la experiencia espiritual del hombre, desde el principio, y sigue eternamente ${ }^{2}$, lo que implica la armonía y el amor entre los pueblos, puesto que Dios crea el ser humano con el amor que el hombre necesita para completar el proyecto de Dios.

Algunos creen que los colores representan el punto de encuentro entre el arte, la ciencia, la filosofía y las religiones, formando un puente entre la física, la metafísica y Dios el Creador ${ }^{3}$, que significa glorificar a Dios por su manera de crear el universo, y por la belleza de colores, con los cuales creó, maravillosamente, sus criaturas en la tierra, sobre todo las aves, las mariposas, las flores y los peces.

Otros piensan que el color es una ciencia independiente, como cualquier otra; y, en Alemania, incluso, se encuentra una facultad especializada en el estudio de los colores, presidida por H.Wohlforth ${ }^{4}$. El color también tiene su papel particular en la representación artística coránica, se emplea en los niveles estructurales, expresivos, sensuales, decorativos, estéticos, y simbólicos de la representación artística coránica, ya que el color, en el Corán, tal vez muestra el poder, la clemencia y la belleza divina que se reflejan y se destacan en la naturaleza. O quizás, señala la vida, la muerte, la esperanza, la frustración, la infidelidad, la fe, la actividad y el pesar. Asimismo, se emplea para señalar diversos significados de forma directa como el verde, el amarillo, el blanco, y el negro o de forma indirecta, como la noche, el día, la luz y oscuridad.

\section{LOS MATERIALES COLORANTES USADOS EN LA ANTIGÜEDAD}

Este tema obtuvo especial interés por parte de los arqueólogos y los eruditos del arte, quienes estudiaron los materiales y colores usados antiguamente para policromar los monumentos egipcios antiguos; observándose, aquí también, el tema de las formas o técnicas aplicadas. Desde la época prehistórica, en Egipto, se utilizaban los colores cuando se pretendía pintar y registrar la vida cotidiana, $\mathrm{y}$ en los textos religiosos, en las paredes de los templos y tumbas, en los que se representaba la vida en el más allá. Entonces, se veía lo que pintaban dos objetivos: uno, religioso y, el otro, mundano. Para conseguir esto se ayudó de la variedad de fuentes de las cuales sacaban los colores, que tenían sus propios símbolos para el egipcio antiguo. Por ejemplo: el color marrón, cercano al rojo, se usaba para la piel del hombre, ya que sale a trabajar y se expone a los rayos del sol. Esto permite diferenciar su piel del de la mujer, que normalmente era amarilla, el mismo color del sol.

Los colores primarios se obtenían de los materiales naturales disponibles, por ejemplo: el blanco, del carbonato de calcio (la tiza) o del sulfato de calcio (el yeso o la escayola); el negro, se producía del carbón vegetal o del hollín. Algunos colores se preparaban del ocre, una especie de óxidos rojos de

\footnotetext{
** La religion islamica alzaba el color verde como simbolo sagrado en las banderas distintas.

2 Baines, J. «Color Terminology and Color Classification: Ancient Egyptian Color Terminology and Polychromy.» En: J. Baines. Visual and written culture in ancient Egypt: 240-262. Oxford: Oxford University Press, 2007.

3 Pfeifer, H. E. L'harmonie des couleurs. Paris, Dunod, 1965. p.13.

4 Burke, K. Language as Symbolic Action: Essays on Life, Literature, and Method. Berkeley: University of California Press, 1968. p.7.
} 
hierro, (los grados de sus colores, van desde el amarillo pasando por el rojo y luego el marrón oscuro) el verde, se obtenía del polvo de la materia prima del cobre como la malaquita, o a través de mezclar el ocre amarillo con la frita azul. El azul, originalmente, se sacaba de la azurita (bicarbonato de cobre) que se encuentra en el Sinaí y en el desierto oriental de Egipto. El que más se preparaba era de la frita azul, conocida con el nombre del azul egipcio, que se preparaba mezclando el cuarzo caliente con cal; luego, se añade el natrón, o el polvo de algunas plantas, o la malaquita, machacada con carbonato cálcico. Digno de mencionar es que la misma mezcla se utilizaba para recubrir la fayenza, que se usaba ampliamente para en fabricar los abalorios, los amuletos y las estatuas pequeñas.

Los estudiosos han clasificado los colores utilizados por el egipcio antiguo en dos tipos.

\section{LOS MATERIALES COLORANTES}

Son las partículas de diversos óxidos de minerales naturales, normalmente son las mezclas entre estos óxidos, antes de policromar, con medios líquidos como la goma arábiga, la cola de animales, clara de huevo, en el caso de la témpera. En el caso del fresco, se usan los óxidos con el líquido solamente sin el medio.

\section{LOS COLORANTES}

Es el extracto coloreado líquido que se infiltra en el material al emplearlo directamente o a través de un intermediario. Normalmente se extrae de plantas o de insectos que viven en los árboles. El artista egipcio, no se limitaba a estos colores, sino que les añadía otros artificiales como: el verde egipcio, el azul egipcio, aunque también importaba otros tipos materiales colorantes.

La operación de policromar las escenas ha evolucionado constantemente, de una época a otra, pues se nota que el artista, durante el Imperio Antiguo, usaba solo cinco colores, que son: el rojo, el amarillo, el blanco, el marrón y el azul; y, en el Reino Medio, utilizaba otros colores, aparte de los anteriormente mencionados, como el verde. También consiguió el artista degradar los colores obtenidos de los óxidos de minerales naturales, que trataremos ahora detalladamente, en los siguientes apartados sobre materiales colorantes y las técnicas de conseguirlos:

\section{Materiales colorantes amarillos}

Este color se empleó para representar al sol y el oro, también para mostrar la piel de las mujeres. Fue utilizado desde la época predinástica. Extendiéndose su uso, llegando a su culminación, durante el Imperio Nuevo, asimismo lo encontramos en la época Saíta o la Dinastía 26.

\section{Ocre amarillo}

Al ocre amarillo se considera el color más célebre del cual se saca el color amarillo. Se compone de goethita con sílice, y minerales de arcilla; probablemente, se encuentra en la limonita, mezclado con un porcentaje de calcita, cuarzo y arcilla y, en este caso, tiende más al color marrón. El ocre amarillo se encuentra, en la naturaleza, en las piedras areniscas, en la zona del desierto occidental, precisamente, en la zona de las minas de hierro del oasis de Baharia; también se encuentra formando las piedras que cubren en el desierto oriental. Ni los ácidos, ni los álcalis diluidos,

5 Douma, M. Pigments through the Ages. Institute for Dynamic Educational Development (IDEA). Disponible en: <http://www.webexhibits.org/pigments> [Acceso el 4 de enero de 2013]. Faulkner, R. 1991. A Concise Dictionary of Middle Egyptian. Oxford, Oxford University Press, 2008.

* Se preparaban los colores complementarios mezclando los primarios como el gris a través del negro y el blanco etc. 
afectan al ocre amarillo. Sin embargo, se cambia al color rojo si se expone a temperaturas altas, puesto que los hidróxidos de hierro se convierten en anhidróxido de hierro, lo que quiere decir que la limonita se transforma en hematita.

\section{Oropimente}

El egipcio empezó a usar el un mineral del grupo de los sulfuros desde comienzos de la Dinastía 18, lo llamaba el amarillo real o el amarillo dorado. Warburton (2004), lo llamó el brillo amarillo, y éste material se encontró en la tumba del rey Tut Ankh Amón.

\section{Materia colorante roja}

Se considera uno de los colores principales que se utilizaron en las pinturas del antiguo Egipto, ya que era el color real que señalaba la victoria. Se empleaba en los textos registrados en las paredes, en los papiros ${ }^{6}$; asimismo, se utilizaba para ciertos textos como en los comienzos de las estaciones, y los inicios de los párrafos; lo usaban para policromar la piel de los hombres y, a veces, se mezclaba con el amarillo para pintar la piel de las mujeres.

El egipcio antiguo aprovechaba el ocre rojo como materia básica para dar el color rojo, y se sabe que éste es la sustancia polvorienta derivada de la hematita, que se encuentra con abundancia en el desierto occidental de Egipto y en Asuán.

\section{Materia colorante blanca}

Se conoció el color blanco, en el antiguo Egipto, desde la época predinástica, y es de los colores antiguos más importantes. Tenía su importancia para los antiguos egipcios ya que los grandes sacerdotes, los religiosos, se lo ponían. También se utilizaba para colorear la ropa y pintar el blanco del ojo, en las representaciones o las estatuas. Así también se empleaba ${ }^{7}$, a finales de la Dinastía 18, para policromar el fondo de las escenas, como también para decorar las vasijas de barro cocido.

El artista consiguió obtener grados de este color y lo usaba para diluir otro color, aquí se detallan los materiales de donde se conseguía el color blanco:

\section{Yeso}

Se utilizó el yeso como una materia colorante blanca en las imágenes egipcias antiguas, y en forma bruta, no tratado con la calcinación, después de mezclarlo con solución de cola de animales.

\section{Calcita}

Warburton (2004) pudo identificar un color blanco de carbonato de calcio en las tumbas de la V Dinastía que se utilizó durante el Reino Medio. Sahlins (1977) mencionó que pudo reconocer carbonato de calcio, como color básico, en numerosas tumbas de épocas distintas, también dijo que es difícil saber si el egipcio antiguo usaba el yeso como color blanco o no, puesto que la materia actual es carbonato de calcio, sea su origen la cal o el polvo de la piedra calcárea, o resultado de la transformación del hidróxido de calcio en carbonato de calcio, a causa del dióxido de carbono.

6 Kay, P. y Maffi, L. «Color appearance and the emergence and evolution of basic color lexicons». En: American Anthropologist 101, 1999: 743-760.

7 Manniche, L.. «The Complexion of Queen Ahmosi Nefertere». En: Acta Orientalia 40: 1970, 11-19. 
El yeso se utiliza después de machacar la piedra calcárea pura y se mezcla con agua, hasta que floten los granitos, para separar los finos de los gruesos ${ }^{8}$, luego los finos se secan y se aprovechan en las pinturas.

\section{Huntita}

Los egipcios antiguos usaban el material de huntita, que es carbonato de calcio y magnesio. Este mineral apareció durante el Imperio Nuevo, y se utilizaba para colorear la ropa de los dioses, ya que es más resplandeciente que el carbonato de calcio. Sin embargo, Sahlins (1977), a través de sus estudios e investigaciones, afirmó que este mineral se encuentra como tachas en el carbonato de calcio, utilizado como color blanco, y no como materia que conocían los egipcios antiguos y la usaban intencionadamente, según las palabras confirmadas por Fischer (1963).

\section{Blanco de plomo (carbonato básico de plomo)}

Se encuentra en la naturaleza en forma de la cerusita.

\section{Material de color azul}

Se conoció en el antiguo Egipto y se utilizaba en las tumbas para representar el agua azul del Nilo, También se usaba para colorear los techos, como si fuera el cielo claro o despejado. Es considerado como un color sagrado, ya que simbolizaba la realidad sagrada, y es el color de la vida, porque el dios de la vida y generación tenía este color. Sus fuentes son:

\section{Azurita (carbonato básico de cobre)}

Es de las fuentes más antiguas de las cuales se sacaba el color azul, se encuentra, en su forma natural, en el Sinaí y el desierto oriental ${ }^{9}$. En condiciones normales, se caracteriza por su persistencia química, pero las altas temperaturas le afectan, lo que hace que el azul tienda a ser negro, también le afectan las disoluciones alcalinas y se disuelve en ácidos.

\section{Azul egipcio}

Este color no es natural, se preparaba artificialmente debido a la escasez de la azurita en Egipto. De los ejemplos pintados con este color, podemos mencionar el caso de las ocas de Médium. Este color es la prueba de que el egipcio evolucionó en la fabricación de los colores. Este color llamó la atención de muchos científicos cuando intentaban llegar a su composición y fabricación pues se encontró que está compuesto de silicato de cobre y de calcio ${ }^{10}$. Se caracteriza por ser resistente bajo condiciones desfavorables: como altas temperaturas y la humedad, porque este color iguala los efectos de todos los álcalis y ácidos.

8 Mathieu, B. «Les couleurs dans les Textes des Pyramides: approche des systèmes chromatiques». En: Égypte Nilotique et Méditerranéenne 2: 2009, 25-52.

9 Sahlins, Marshall, «Colors and cultures». En: J.L. Dolgin, D.S. Kemnitzer, D.M. Schneider (eds.), Symbolic anthropology. New York: Columbia University Press, pp. 165-180. Cf. in Semiotica 16, 1976: 1-22.

10 Warburton, D. «The terminology of ancient Egyptian colours in context». En: L. Cleland, K. Stears, G. Davies (eds.). Colour in the ancient Mediterranean world. Oxford: Hedges. BAR International Series, 1267: 2004, 126-130. 


\section{Materiales de color verde}

Este color tenía una importancia especial este color para el egipcio antiguo pues presentaba la naturaleza eterna, en la cual creía el egipcio antiguo, y se preparaba para vivirla. Fue el color de la resurrección, y un color sagrado que se utilizó para colorear los árboles, la planta del papiro, y las flores; también fue el símbolo de la juventud y la vitalidad. Sus fuentes son:

\section{Malaquita}

Es carbonato básico de cobre, de los materiales secundarios de cobre, importantes, y ampliamente extendidos, porque se encuentra en las partes superiores de las zonas de los óxidos, de vetas de cobre, acompañando la azurita y el sulfato. Este mineral se encuentra en la península del Sinaí, en el desierto oriental y en distintos sitios del desierto occidental. En general, fue utilizado desde la época predinástica.

\section{Verde egipcio}

El antiguo egipcio preparaba industrialmente el material verde, que se utilizó solo o con cloruro de cobre. Este tipo de materia se usó en las tumbas del Reino Medio y en la época Saíta. En su composición, el verde egipcio, se parece al azul egipcio, pero se diferencian en la temperatura necesaria para producirlo, que es más alta que $950{ }^{\circ} \mathrm{C}$.

\section{Materiales de color negro}

El negro es uno de los colores primarios, el egipcio antiguo lo utilizó para colorear el pelo de las mujeres, las pelucas y como cosmético o máscara (Kohl) alrededor de los ojos de maquillaje. También se usaba como un color funerario, expresando la resurrección y la eternidad, por lo tanto, se encuentra en las tumbas. Para representar la tierra negra de Egipto, el egipcio lo aprovechaba para este motivo, ya que durante algún tiempo, Egipto llevaba el nombre de Kemet o la tierra negra. El mineral básico que forma este color es el carbono, que en la naturaleza se encuentra en diferentes formas:

\section{Hollín}

El egipcio antiguo utilizaba el hollín, que lo sacaba de la superficie de los utensilios de cocina; o cuando quemaba las resinas. Lo ponía en superficies alisadas y lo mezclaba con goma arábiga, para juntar sus partículas y la superficie donde se tenía que pintar.

\section{Carbón vegetal}

El carbón vegetal se usaba como color negro después de mezclarlo con la cola de animal, y es menos puro que el hollín.

Los factores de deterioro que afectan a los materiales de colores son:

\section{Factores internos}

Incluyen la diferencia de la naturaleza y características de la textura parietal de los grabados, el soporte de la representación, las capas preparatorias, la capa de color (la presencia de sales en los materiales de construcción, los defectos en la técnica durante el proceso de la ejecución, el efecto del agua subterránea, y la de filtración, y los daños que provoca el ser humano o el daño biológico). 


\section{Factores externos}

Contienen la diferencia de temperatura y humedad relativas, la erosión, los desastres naturales, las inundaciones, la lluvia, y la contaminación del aire.

\section{LA SIMBOLOGÍA DE LOS COLORES PARA EL EGIPCIO ANTIGUO}

Los colores tenían significados simbólicos en las representaciones del egipcio antiguo: el color negro era el color de la tierra fértil y la fertilidad, la renovación y el mundo subterráneo. El rojo se refiere al fuego, la sangre ${ }^{11}$, el desierto y el caos, porque es el color del dios Seth. El verde llevaba significaciones tácitas relacionadas con los cultivos floridos, con la vitalidad y la renovación, por eso las máscaras de los sarcófagos, en la Dinastía 20, se pintaban con el color verde para comparar al difunto con el dios Osiris, a fin de garantizar el proceso de la resurrección.

Osiris normalmente se representaba con piel verde, como símbolo de su regreso a la vida (regeneración). Mientras el amarillo, se relacionaba con el sol, y simbolizaba los cuerpos de los dioses. El azul, se asociaba con el agua y el cielo, era familiar utilizarlo para pintar los cuerpos y las barbas de los dioses, así como también sus pelucas.

\section{LOS COLORES Y LAS RELIGIONES}

Cuando se ven a los sacerdotes ortodoxos orientales que llevan vestido negro, y un cubrecabezas del mismo color, probablemente este tema está relacionado con el luto y la muerte. Sin embargo, los religiosos católicos, e incluso las monjas, prefieren el negro por ser discreto y simple; mientras que los monjes protestantes, como los luteranos, llevan el color blanco o gris como reacción contraria a la iglesia católica; y Los religiosos judíos ortodoxos, se visten con mantos negros y largos, y sombrero negro también, durante las ceremonias religiosas y los acontecimientos importantes, para reflejar su humildad y modestia.*

\section{SIGNIFICADO DE LOS COLORES EN LA ÉPOCA COPTA}

Los colores utilizados por el egipcio antiguo, en las representaciones de la tumbas antiguas, y sus grabados, es un tema debatido, pues algunos suponían que los materiales de los colores, a veces, eran substancias que dejaron de existir e incluso no conocemos su naturaleza. Pero resulta que no es el caso que tenemos, puesto que estos materiales se sometieron a estudios, y fueron analizados repetidamente. Se encontró que, a excepción de un número limitado de materias, los demás o bien son materiales de minerales naturales machacados en polvo, o son materiales preparados industrialmente. Aún así, no quiere decir que cada color tuviera una referencia simbólica, pues algunos de estos colores se usaban para cumplir su función en la decoración, y como la simbología era de las características del arte egipcio antiguo, entonces esto significa que habían ciertos colores que tenían este carácter simbólico, y sus colores básicos fueron: el rojo, el negro, el blanco, el azul, el amarillo, y el verde.

Como se vé, los egipcios han preferido los colores primarios para expresar la simbología, tal vez porque ellos utilizaban colores distintos de los primarios, lo que será contrastado con la naturaleza.

11 Graciela Gestoso Singer, Color in Ancient Egypt, [en línea]. Terrae Antiqvae, 6 de diciembre de 2010. <http:// terraeantiqvae.com/profiles/blogs/color-in-ancient-egypt>. [Acceso el 4 de diciembre de 2013].

* Los musulmanes prefieren el color verde para cubrir sus tumbas y mausoleos y se encuentra en sus mezquitas. Es conocido que el Islam no tiene un específico color, tal vez algunos asocian el verde con dicha religión porque el profeta Mohamed lo prefería porque relaja la vista y se relaciona con la naturaleza. 
Los dos colores más utilizados eran el rojo y el negro, que los usaban para colorear los personajes importantes y escribir en jeroglíficos ${ }^{12}$. En la religión cristiana, los colores se emplean en insignias rituales, como los carteles o pancartas, la ropa, etc. y, menos todavía en el arte cristiano, mientras en la Biblia son raras las referencias a los colores y sus símbolos.

Los colores, y su simbología, se centraban no solamente en Egipto, sino también en otras zonas como: Canaán, Fenicia, con los israelitas (en el Antiguo Testamento) Irak (las civilizaciones de Mesopotamia), con los griegos, y los romanos; y luego, con los cristianos (en el Nuevo Testamento) y en las artes coptas y bizantinas. Aunque el caso se concentrara en Egipto, cuando usaban los colores, lo hacían con los mismos significados y símbolos antiguos, por ejemplo: en la tumba funeraria número 21 Tuna el Gabal del desierto, de Darwa, en Mallaui, de la provincia de Minia, se ve la cara de la muchacha (Electra) de color blanco, como es costumbre egipcia antigua para representar a las mujeres, mientras que para el hombre (Lorestos y Bellar), era el color rojo-marrón.

Se nota también la similitud entre la simbología de algunos colores en la Biblia (en los dos testamentos), y en el cristianismo (el arte de los iconos, en las representaciones parietales policromadas), con la simbología de los colores de las civilizaciones antiguas.

Pues en la Biblia, encontramos referencias al color blanco con sus significaciones; el rojo, refiriéndose al Mar Rojo, y su simbología, en el pensamiento religioso judío-cristiano de la misma manera. Curiosamente, desaparecieron de la Biblia los colores: azul, verde, negro y amarillo, aunque éste último se puede palpar su simbología en el concepto del desierto.

\section{LA SIMBOLOGÍA Y LOS COLORES}

El ambiente egipcio, que rodeaba al egipcio antiguo, y que fue rico en sus elementos y componentes, tuvo su influencia para obtener muchos conceptos relacionados o bien con la vida cotidiana o bien la vida religiosa ${ }^{13}$. Respecto a los colores, el egipcio obtuvo sus conceptos sobre el conjunto de los colores, usados en sus obras artísticas, que tenía cierta influencia en su vida religiosa, por ejemplo: la sucesión del día y la noche ${ }^{14}$, fue uno de los fenómenos más importantes que le ayudaron a formar su concepto de los colores claros y obscuros. Así también el color del disco solar, en la salida y la puesta del sol, o el color de la sangre, le ayudaron en formular un concepto del color rojo. Asoció el azul con el cielo y el agua, mientras que el color verde, fue la representación del concepto del verdor, el crecimiento, el florecimiento, la vitalidad y la vegetación. Cuando el amarillo, era reflejo del desierto inmenso que le rodeaba ${ }^{15}$.

12 Lucas A, Ancient Egyptian Materials and industries. Londres, 1962. p.134.

13 Aufrere, S. L'univers mineral dans la pensee egyptienne. El Cairo: Institut Francais d'Archeologie Orientale. 1991.

14 Graciela Gestoso Singer, Color in Ancient Egypt [en línea]. Terrae Antiqvae, 6 de diciembre de 2010. <http:// terraeantiqvae.com/profiles/blogs/color-in-ancient-egypt>. [Acceso el 4 de diciembre de 2013].

15 Berlin, B.Kay.P. Basic color terms: their universality and evolution. Bekeley: University of California press, 1991.

- Sahlins, Marshall, «Colors and cultures» En: J.L.Dolgin, D.S. Kemnitzer, D.M Schneider (eds), Symbolic anthropology. New York, 1977. Columbia university press, pp. 165-180 Cf. En: Semiotica 16 (1976): $1-22$.

- Baines, j, «Color Terminology and color Classification: Ancient Egyptian Color terminology and polychromy». En: American anthropologist, 1985, 2: 282-297.

- Baines, $\mathrm{j}$ «Color terminology and color classification: Ancient Egyptian color Terminology and polychromy.» En: J. Baines Visual and written culture in ancient Egypt. Oxford: Oxford University press, 2007, pp. 240 -262. Brusatin, M.A History of color. Boston: Shambhala publications, 1991.

- Burton, D. «Red, Yellow and Blue: The Historical Origin of Color Systems». En: Art Education 45, 6, 1992. 
La simbología es la demostración de un objeto a través de la existencia de una relación entre dos cosas, lo particular con lo general o lo concreto con lo abstracto.

De los colores básicos utilizados por el egipcio antiguo: el azul, el rojo, el amarillo, también usaba numerosos colores que no tenían nombres como: gris y marrón. Mientras que los colores más importantes empleados en la arquitectura, y las artes egipcias antiguas (sean colorante de pintura o piedras) son: el blanco, el negro, el rojo, el amarillo, el azul, y el verde ${ }^{16}$.

Las estatuas de maternidad prehistóricas eran de color verde, símbolo de fertilidad, o de color rojo símbolo de la vida (la sangre). Las decoraciones de la cerámica de Nagada, (uno de los famosos enclaves del Neolítico en la provincia de Qena), en la cultura de Nagada I, eran de color blanco, color del Alto Egipto; mientras en Nagada II, eran de color rojo, símbolo del Bajo Egipto. Los colores se habían utilizado para imitar los colores de los materiales naturales y vegetales, con los que se construyeron los diferentes elementos arquitectónicos, como símbolo del universo y sus elementos, sobre todo en los templos de los dioses. Por lo tanto estos colores formaron, en la arquitectura, una representación del universo y sus fenómenos naturales, y el mejor ejemplo de este caso son los colores de las puertas de los templos del Antiguo Egipto, donde el templo era una imagen reducida del mundo, pues su suelo es la tierra negra fértil de Egipto, con sus plantas. Alrededor del templo la tierra es amarilla, significando el resto del mundo con sus desiertos áridos, mientras que el techo es el cielo azul, con sus brillantes estrellas, amarillas o blancas.

Los colores, en algunas escenas, en las artes o en las estatuas, demostraron la personificación de algunas características de dioses, y la variación de las clases y razas, como el significado de los colores, y la representación de las razas distintas ${ }^{17}$.

\section{Color negro $\mathrm{kmt}$}

Se utilizó para pintar las momias como símbolo de la resurrección y la vida eterna. A veces Osiris era representado con el color negro. Las fuentes de este color son varios materiales carbónicos: el carbón, el sulfato de calcio y el oxido de magnesio, disponible en el Sinaí. Normalmente el negro se emplea para confirmar las formas y destacar los diseños. Se pintó con este color al dios Osiris ${ }^{18}$, como dios del mundo subterráneo oscuro y de los muertos. También reflejaba el concepto de la fertilidad y la resurrección, pues el color se asoció con la vida y la fecundidad por el negro limo fértil, El dios Min, también se relacionó con el color negro pintando su piel con dicho color o llamarlo con el calificativo negro, que lleva el concepto de la fertilidad y el crecimiento, en su aspecto fecundo, representado en «ka-mut-f», o el toro de su madre ${ }^{19}$. Para el egipcio antiguo el negro simbolizaba la muerte, por lo tan-

16 Kay, p. Maffi, L. «Color appearance and the emergence and evolution of basic color lexicons». En: American Anthropologist 101: 199, 743-760.

- Mathieu, B. «Les couleurs dans les Textes des Pyramides: approche des systemes chromatiques». En: Egypte Nilotique et Mediterraneenne 2: 25-52, 2009.

17 Lucas A, Ancient Egyptian Materials and Industries, London, 1962, p.134.

- Dolinska, M. «Red and blue figures of Amun». En Varia aegyptiace 6: 3-7. 1990.

- Mertz, B, Red Land, Black Land. Londres: Hodder and Stoughton 1966.

- Pastoureau, M- Simonnet, D. Breve Historia de los Colores, Barcelona: Paidos, 2006.

- Robins, G. «Color symbolism». En: The oxford Encyclopedia of Ancient Egypt. Oxford: Oxford Yniversity press, 2008.

- Warburton, D. 2004. « the terminology of ancient egyptian colours in contexts». En: L.Cleland, K. Stears, G. Davies (eds). Colour in the ancient Mediterranean world. Oxford: Hedges. BAR International series, 1267: 126-130.

- Kees, H, Farbensmbolik in agyptischen Religiosen Texten, NAWG 11: 413-479, 1943.

18 Griffiths, J.G. The origins of Osiris and his cult. Leiden: Brill, 1980.12-13.

19 Gayet, A, Le temple de Louxor MIFAO, 15, 1894. pls . 62-69. 
to es un color ritual del Gran viernes, probablemente represente el pecado que conduce a la muerte.

En física, la negrura quiere decir perder el color, pues es el color de la oscuridad, el silencio, la desesperación, el fracaso y la muerte. Es símbolo de la tristeza, de la preocupación, del fracaso, También es el color que representa la injusticia, la ira, el pecado, el ateísmo, la infidelidad, etc.

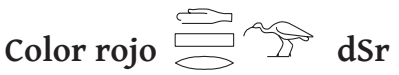

Se relacionó este color con la corona del Bajo Egipto, con el enrojecimiento de los ojos o el fuego, o con el color del natrón rojo y la madera roja, o bien con la grasa roja y el aceite rojo; también con los granos de la cebada roja, que se utiliza para producir la cerveza.

Y como el rojo es el color de la sangre, es un color ritual para celebrar los aniversarios de los santos mártires, también se utiliza en los ritos del día de Pentecostés como el color del fuego. Generalmente este color señala la fuerza, el amor, el sufrimiento, la justicia, que es el color más común, y da una dinámica fuerte puesto que atrae, como color vivo.

Asímismo, el egipcio antiguo lo utilizó como color del mal, ya que representó al dios «Seth» con el color rojo. Por lo tanto, los que tenían piel de tonalidad roja, se consideraban personas malditas, lo mismo ocurría con los animales. Sin embargo, el color rojo, con tendencia al azul (el carmesí), era símbolo de la Virgen y, en el Apocalipsis, simbolizó el horror y la destrucción, como también la gloria, el sacrificio, y la sangre en la cruzen el cristianismo. El carmesí se mencionó en El Antiguo Testamento en la historia de Saúl ${ }^{20}$, también se refiere a la casta mujer y a Jerusalén.

El ejemplo del rojo en el Apocalipsis muestra que si los colores, aunque son pocas las referencias, existían en la Biblia, por ejemplo: «[...] y cuando abrió el segundo sello, oía la segunda criatura viviente decir jven! Y salió otro, un caballo de color de fuego y al que iba sentado sobre él se le concedió quitar de la tierra la paz para que se degollaran unos a otros, y le fue dada una gran espada.»

También en el Apocalipsis hay referencias al color rojo relativas a la aparición de señales en el cielo: «Miren un dragón grande de color de fuego con siete cabezas y diez cuernos, y sobre sus cabezas siete diademas» (Rev. 6: 3 y 12: 3). Por esto el rojo apareció en el arte copto en general y en los manuscritos en especial.

Este color se forma del óxido de hierro de sus diferentes grados y se encuentra en el desierto occidental y oriental de Egipto ${ }^{21}$.

Es el color más común y se utilizó con abundancia, es uno de los colores del espectro solar y los estudiosos de las artes lo consideran dentro de los colores primarios ${ }^{22}$, Es el color del fuego, de la sangre, que aumenta la excitación provocando presión y respiración profunda porque es el color de la vitalidad y dinamismo, y tiene una gran influencia en el carácter humano, sus gustos y temperamentos. A este color lo consideran del primer grupo clasificado por Young en el año $1802^{23}$, que es el grupo de sensibilidad a las ondas largas que producen una sensación llamada el «color rojo». Antiguamente los escribas, en la civilización egipcia antigua, escribían los términos de contenido malo con color rojo como Apofis y Seth , mientras escribían el resto de los textos con la tinta negra.

El desierto, para el egipcio antiguo, se representaba con la forma de una montaña de tres cimas grandes con valles en medio, este signo se pintaba con el color rojo marcado con un borde marrón,

20 Yuhanah el Najili (cura) Interpretacion del Apocalipsis.

21 Gamal Hermina op .cit.: 832.

22 Shehata, Ahmed y Gouda, Abdel Aziz, Quira'at fi Attazawok Alfanni wa Tarikh Alfann, El Cairo, s.f.: 120.

23 <http://www.ridingthebeast.com/articles/colors>.

- Douma, M. 2008. Pigments through the Ages. Institute for Dynamic Educational Development (IDEA). [en línea] <http://www.webexhibits.org/pigments>. 
indicando la montaña cuando se ve de lejos bajo la luz del sol. También el ave fénix se representaba pintada de color fuego.

Desde luego la historia egipcia está llena de casos que tienen relación con el color rojo, por ejemplo el dios Ra se asoció estrechamente con este color que expresaba la esencia, la naturaleza y la entidad del sol y se conocía en el Libro de los Muertos con el nombre del rojizo ${ }^{24}$.

El tocado Nemis se hacía de tela blanca con rayas rojas. Los vasos de comer se fabricaban de esquisto, pizarra, de mármol blanco y raramente de mármol rojo, ya que es el color de la mala fortuna y, en las revelaciones de San Juan, en la ciudad nueva, había cornalina, símbolo de victoria sobre los enemigos ${ }^{25}$.

A nivel sentimental el rojo es el color del amor ardiente, del optimismo, la fuerza y la juventud. A veces expresa la alegría y se lleva en las fiestas. Los genios se visten de rojo también.

\section{El color verde $\int_{2}^{2}$ wADt}

Se utilizó para representar los colores fríos o suaves: el verde y el azul claro, se utilizaba para designar el mundo de las plantas y la vegetación, se personificó en la cara y el cuerpo del dios Osiris, dios del cultivo, de la renovación, de la fertilidad, del crecimiento, de las semillas crecientes, del mundo del más allá lleno de riquezas, y símbolo del mundo celeste ya que era verde tirando a azul. Curiosamente Osiris se llamaba «El gran verde» cuando le devolvió la vida a la diosa Isis y pintaron su cara con dicho color. Es un término asociado con la planta del papiro y con la diosa del Bajo Egipto «Wadiet» que su nombre significaba, la florida, la reanimada, la brillante, la joven, la verdeante, la creciente ${ }^{26}$, y su símbolo era la cobra.

El color verde es el color del mundo vegetal, de la primavera. Con todo lo relacionado con el verdor, el florecimiento y la prosperidad, pues representaba la vida y la resurrección, y como viene en el epíteto de «La verde de los años» de la reina Hatshepsut escrito en su obelisco en Karnak, y también en el término de W3dt-Wr, quiere decir el gran mar, posiblemente se refiere al Mediterráneo.

Era el color que representaba la victoria de la vida sobre la muerte, y que es un color ritual de las triadas en algunas ceremonias, se relaciona con la vida, sus símbolos y su naturaleza con sus árboles, sus plantas, su limo y con las hojas de las palmeras. Se forma principalmente de la malaquita y es un color secundario formado por el amarillo y el azul, Young lo clasifica en el segundo grupo que es de sensibilidad a las ondas lumínicas medias que producen el efecto llamado «el color verde» ${ }^{27}$.

Las estatuas de Ushabtis se pintaban con el color verde o azul porque, según se decía, todo lo que se fabricaba era de color verde, ya que este color significa la fuerza y la salud del cuerpo.

24 Kees, op. cit.: 448-449.

$25<$ www.riding the beast .com/article/colors>

- Douma, M. 2008. Pigments through the Ages. Institute for Dynamic Educational Development (IDEA). [en línea] <http://www.webexhibits.org/pigments>.

26 Ibid.: 239.

27 Dennis Bratcher: the meaning of church colors.

- Graciela Gestoso Singer. Color in Ancient Egypt, Terrae Antiqvae, 6 de diciembre de 2010, [en línea]: http:// terraeantiqvae.com/profiles/blogs/color-in-ancient-egypt.

- dividedheart.com/index.php?topic=2074.0; wap2

- www.crivoice.org/symbols/colorsmeaning.html

- www.crivoice.org/colorsof.html

- www.Cresourcei.org/symbols/symbols.html.

- www.religionfacts.com/islam/symbols.html.

- www.painting.about.com /b/a/238378.html 
Este color también se relacionó estrechamente con los símbolos de la muerte, la destrucción, la descomposición, el barro, y la oscuridad, y cuando este color tendía hacia el amarillo adquiría vitalidad y alegría, y si tendía hacia el azul, significaba descripción.

Se usó en el arte cristiano como uno del símbolo de la paz en el libro del Éxodo ${ }^{28}$. Los hebreos lo llaman Yoroa, y en griegos: chloyos. Los griegos lo ofrecían a la diosa Afrodita que representaba la fuerza de la juventud y vitalidad.

La Biblia no señalaba un significado concreto a este color, pero se sobreentiende que expresa la tranquilidad, profundidad que iluminan el cielo, el palacio de la gloria divina. Se mencionó en el Apocalipsis: «...y cuando abrió el cuarto sello, oí la voz de la cuarta criatura viviente decir ¡ven ! y vi y ¡miren ! un caballo pálido, y el que iba sentado sobre él tenía el nombre muerte y el Hades venía siguiendo de cerca, y se les dio autoridad sobre la cuarta parte de la tierra, para matar con una espada larga y con escasez de alimento y con plaga mortífera y por las bestias salvajes de la tierra ${ }^{29}$ (Re.6:7-8).

«Caballo verde», en otras traducciones significa «caballo pálido», mientras que en copto es amarillo, de allí se entiende que el color del caballo es verde tirando a amarillo o verde pálido, pues el color verde es el color de la vida que sin verdor no hay vida. Los cristianos rezan la oración de los muertos y dicen: «que estén en un sitio verde sobre el agua del descanso» y en la «oración del tercero» para los muertos, se sirve agua, perejil y pan para decir a los familiares del difunto» que todavía está vivo».

\section{Color naranja}

Goethe dice que es el color que atrae por su energía .No es nada extraño que este color produce, para los hombres intelectuales, una sensación de violencia y aspereza, mientras para los iletrados les produce severa maldad. Si dejamos a las naciones bereberes y a los niños elegir los colores, seguramente optaran por el color naranja ${ }^{30}$.

Es un grado de color indispensable para decorar las obras artísticas, y se utilizó en el arte copto porque es próximo a los dos colores el rojo y el amarillo.

\section{Color amarillo}

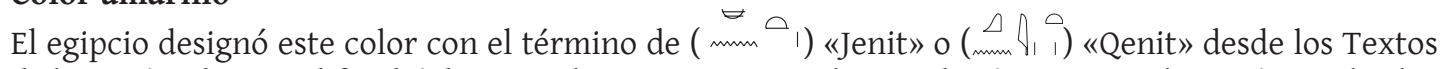
de las Pirámides y se difundió durante el Imperio Nuevo. El segundo término se relacionó con el color del sol, con las caras de las formas, y con un tipo de oro que es el amarillo. También se relaciona con una de las enfermedades de los ojos, cuando los ojos lucen amarillentos como síntoma de la hepatitis.

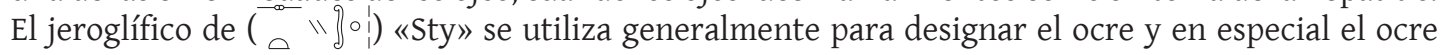
amarillo, y a veces se refiere también al color amarillo y el rojo.

Como el color de luz, probablemente la luz amarilla, representaba la naturaleza divina, aunque como el amarillo no es blanco puro, a veces simbolizaba también la corrupción y la decadencia. Este color desempeñó un papel principal en el arte funerario egipcio y del cual se hicieron las estatuas de las ofrendas y los sarcófagos y lo consideraban símbolo de la santidad que emana de la luz divina y de los rayos del sol. Es un color que refleja la intensidad del sufrimiento y el amarrillo dorado expresa la gloria celestial, símbolo del cuerpo de $\operatorname{dios}^{31}$. Su fuente, es el óxido de hierro ${ }^{32}$.

28 Abdelmalek et al., 1994, Kamus Alketab Almuqaddas, Dar Ethaqafah, El Cairo.

29 Apocalipsis 6: 7.

30 Gameal Hermina, op. cit:: 836.

31 Fathia Abdu Alsalmi op .cit.: 5.

32 Gamal Hermina, Doctoado op .cit.: 836. 
Según si se encuentra el amarillo o no en la obra artística se puede deducir el significado: si se ve en los árboles, da efecto de aridez y sequía; en la atmósfera terrestre, da sensación de una tempestad; cuando los rayos del sol amarillos caen sobre la tierra o las plantas, producen efecto de calor y vitalidad.

Es del grupo de los colores principales, entra en su composición el color verde, fue mencionado en el Apocalipsis (21-19).El color amarillo es de los colores más alegres porque es muy brillante y espléndido. Es la Culminación del brillo y la iluminación porque es el color del sol, la fuente de luz, que da el calor, la vida, la vitalidad y la alegría. Los egipcios antiguos lo consideraron símbolo del sol y protección de las enfermedades. Por otro lado, el color amarillo tiene otro significado que contrasta lo anteriormente mencionado, pues éste expresa el pesar, la tristeza, la marchitez, la pereza, la muerte y la destrucción. Posiblemente este significado tiene relación con el otoño, el desierto y la muerte de la naturaleza.

Es el color del oro, un metal divino que dio a Tutankhamon y, los demás faraones, la vida eterna; como el sol, y los demás dioses, también era muy importante en los símbolos funerarios llamando al lugar, donde se hacían las estatuas de las ofrendas y los sarcófagos, la casa del oro. En el arte egipcio antiguo se utilizaba con sus distintos grados, y los coptos lo empleaban en su arte señalando el otoño de la vida y la debilidad espiritual del hombre.

\section{Color dorado $\sqrt{\mathrm{r}} \mathrm{m}$ ?}

Símbolo de realeza, se utilizaba con frecuencia en el antiguo Egipto, era uno de los apodos que llevaba el faraón «Hur Neb» o bien «Horus el de oro», también algunos de los coptos lo llevaban en su nombre, como San «Abanub», o bien, el padre de oro; otro Santo de la iglesia egipcia, se llamaba San Juan, «el de la boca de oro». En el templo de Salomón los muebles estaban cubiertos con láminas de oro (Éxodo 25): el dorado señala los valores y virtudes verdaderos (51.4) y. Rev. ${ }^{33}$.

Al contrario que los egipcios antiguos ${ }^{34}$, los coptos no lo utilizaban a menudo debido a su elevado costo, ya que los coptos al principio eran pobres.

\section{Color blanco $\overbrace{\odot}^{2}$ HD}

Simboliza la tristeza y el sufrimiento. El egipcio antiguo, lo llamaba el símbolo de la paz, de la pureza, de la castidad de la discreción y del respeto. El color de la corona del sur, era blanco. El primer muro,

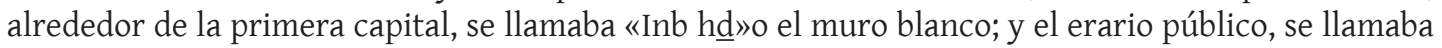
«pr hd » o la casa de la plata, o la casa blanca. También, el color de la ropa de los sacerdotes egipcios, era el lino blanco ${ }^{35}$. La diosa Nejbet, protectora del Alto Egipto, se relacionó con el color blanco y se muestra claramente en sus epítetos, como la «Blanca», asociado originalmente con el color de sus plumas blancas, y también, por su relación con la luna de color plateado ${ }^{36}$. El blanco, es símbolo de pureza, inocencia, y santidad, pues es el color de las ceremonias de Navidad y Pascua. Es un color que se utiliza para dar la sensación de fidelidad, pureza, claridad y sinceridad, características que se manifestaron en los ángeles, los santos y los mártires. Su fuente es el carbonato de calcio y se utilizaba en las piedras calcáreas, areniscas y la plata.

33 Apocalipsis 6: 5; 13:14.

34 Abdel Aziz Saleh op. cit.: 28.

- Grombrich E.H. The story of art. Oxford 1991, p.76.

35 Soniron, Serj. Los sacerdotes en Egipto. Trad. Essa Tanus. Damasco, 1994.

36 Farouk, Azza. Al Elahatan Nekhbet wa Wadjet munz Akdam Al Osur wa hatta nehayat Al Dawlah Alhadithah, [tesis inédita], El Cairo, 1997, p.2. 
En el cristianismo, es el color del sacerdocio, en el Apocalipsis, se menciona un caballo blanco»: ... y ví y jmiren! Un caballo blanco, y el que iba sentado sobre él, tenía un arco y le fue dada una corona y salió venciendo, y para completar su victoria, y cuando abrió el segundo sello, oí a la segunda criatura» (Rev. 6:2-3)

Desde el punto de vista físico, el color blanco contiene todas las ondas de los colores, a saber: cualquier objeto que refleja todas las ondas al ojo, se ve negro; mientras, desde una perspectiva psicológica y social, este color es de pureza, salvación, claridad, amor, bondad, verdad justicia, pues es un color que contrasta con el negro.

\section{Color azul $\ominus 1]$}

Su fuente es la composición de sílice, cobre, silicato de calcio, polvo de la azurita y carbonato de cobre azul. Simboliza el azul la eternidad infinita, color del cielo, y símbolo del mismo, se usa como símbolo de la verdad; es el color que significa la aceptación, como el color de la ceremonia de Navidad. El egipcio antiguo, lo llamó el azul real, el azul claro, pues, era el símbolo de los reinos del cielo, también representaba a la Virgen, la reina del cielo, y el conocimiento iluminado. Es un color que marca las dimensiones, de un sentimiento con la profundidad, representa el temor a Dios, la religiosidad, la oración, la meditación, y refleja la confianza e inocencia, es un color conveniente para la tranquilidad.

Hay un icono donde se manifiesta esta simbología, que es el icono de la visita de San Antonio a San Pablo de siglo IV, donde San Pablo vivía aislado en el desierto oriental, cerca del Mar Rojo. En este icono ${ }^{37}$, se ven claramente algunas de las características del arte copto temprano, y aparecen varios símbolos, como la simbología de los colores, pues el fondo de la escena está dividido en dos mitades: uno verde y, el otro, es dorado; lo que significa, la tierra y el paraíso, sucesivamente. San Pablo tiene una barba blanca larga, lleva una túnica de trenzas de hojas de palmeras, y dos de los leones, están a sus pies, como símbolo de fuerza, hegemonía y dominio que se ven en la mirada de los leones al Santo; mientras San Antonio, lleva el uniforme de los monjes, sujetando en una de sus manos un rollo de papiro con escritura árabe.

\section{Color púrpureo}

Es el color del luto y el arrepentimiento, por lo tanto es color ritual de la navidad, y el ayuno de cuaresma. Es un grado próximo al rojo o al color del vino. Se usaba mucho en el arte copto, porque hay una opinión que dice, que el vestido que llevaba Cristo durante sus pasiones, era de color púrpura. Se encontró este color en el tejido copto, lo que significa que se empleó en el arte copto temprano, y como este color es el color de vino, y en el credo cristiano, representa el color de la sangre de Cristo ${ }^{38}$, el color se citó en el Apocalipsis: «Y la mujer está vestida de púrpura y escarlata y estaba adornada con oro y piedra preciosa y perlas, y tenía en la mano una copa de oro que estaba llena de cosas repugnantes y de las inmundicias de su fornicación» (Rev. 17:4).

\section{Color marrón}

Es un color de la muerte espiritual.

37 Graciela Gestoso Singer, Color in Ancient Egypt, Terrae Antiqvae, December 6th, 2010, online: http://terraeantiqvae.com/profiles/blogs/color-in-ancient-egypt.

38 Coamal Hermina, op.cit.: 836. 


\section{Color gris}

Es el color del polvo, por eso a veces se usa para representar la penitencia y también para el ayuno de cuaresma ${ }^{39}$.

\section{CONCLUSIONES}

En resumen, el mundo que vemos está lleno de color. El color es importante en el arte y culturas de todo el mundo. Cada persona percibe un color diferente. Esto es debido a la tradición, la religión y su simbolismo afecta nuestro estado de ánimo cuando lo contemplamos de una manera inconsciente. La investigación también ha demostrado que la mayoría de los colores tienen asociaciones positivas y negativas ligadas a ellos. Por lo tanto, aunque algunos colores tienen connotaciones negativas (tales como el negro para un funeral o para mal), estos efectos negativos generalmente son provocados por circunstancias específicas. En el Antiguo Egipto, el color fue considerado una parte esencial de la «cosmovisión egipcia».

Al lo largo del análisis que hemos desarrollado sobre el uso del color como emisor de diferentes mensajes, constatamos que el artista copto consiguió, a través del simbolismo, crear un modo nuevo de tratar con el antiguo legado egipcio, y grecorromano, para conseguir una fusión entre estas artes y el pensamiento religioso cristiano; de este modo, surgirá un arte con características sin precedentes. En este arte, el artista copto no pudo olvidar su pasado, pues aprovechó lo que él quería de las civilizaciones y artes anteriores, produciendo un arte propio.

\section{BiBLIOGRAFÍA}

ABDELMALEK, B. et al.

1994 Kamus Alketab Almuqaddas. Dar Ethaqafah, El Cairo.

AUFRERE, S.

1991 L'univers mineral dans la pensee egyptienne. El Cairo: Institut Francais d'Archeologie Orientale.

FAROUK, A.

1997 Al Elahatan Nekhbet wa Wadjet munz Akdam Al Osur wa hatta nehayat Al Dawlah Alhadithah. [tesis inédita], El Cairo.

BAINES, J.

1985 «Color Terminology and Color Classification: Ancient Egyptian Color Terminology and Polychromy». En: American Anthropologist, New Series 87.

2007 Color Terminology and Color Classification: Ancient Egyptian Color Terminology and Polychromy.» En: J. Baines. Visual and written culture in ancient Egypt. Oxford: Oxford University Press.

BALLET, P.

1990 «Ceramic, Coptic», En: The Coptic Encyclopedia vol II. Aziz S. Atiya, editor-in-chief. New York: Macmillan Publishing Co.

BERLIN, B. y P. KAY

1991 Basic color terms: their universality and evolution. Bekeley: University of California press.

BURKE, K.

1966 Language as Symbolic Action: Essays on Life, Literature, and Method. Berkeley: University of California Press.

39 www.religionfacts.com/christianity/symbolscolours.html

- www.teachinghearts.org/dre17httcolour.html.

- www.cresourcei.org/symbols/sybols.html

- www.webexhibits.org/pigments/indiv//coluour/reds2.html. 
BURMESTER, O. H. E.

1967 Egyptian or Coptic Church a detailed description of her rites. El Cairo.

BURTON, D.

1992 «Red, Yellow and Blue: The Historical Origin of Color Systems». En: Art Education 45(6).

CHEVALIER, J. y A. GHEERBRANT

1994 A Dictionary of Symbols. Cambridge: Basil Blackwell Inc.

DOLINSKA, M.

1990 «Red and Blue Figures of Amun». En: Varia Aegyptiaca 6: 3-7.

DOUMA, M.

2010 Pigments through the Ages. Institute for Dynamic Educational Development (IDEA). Disponible en: <http://www.webexhibits.org/pigments> [Acceso el 4 de enero de 2013].

FAULKNER, R.

1991 A Concise Dictionary of Middle Egyptian. Oxford, Oxford University Press

FISCHER, H. G.

1963 «Varia Aegyptiaca: 1. Yellow-skinned Representations of Men in the Old Kingdom». En: Journal of the American Research Center in Egypt 2: 17-22.

GAYET, A.

1894 Le temple de Louxor MIFAO, 15.

GESTOSO SINGER, G.

2012 Color in Ancient Egypt, [en línea]. Terrae Antiqvae, 6 de diciembre de 2010. <http://terraeantiqvae. $\mathrm{com} /$ profiles/blogs/color-in-ancient-egypt>. [Acceso el 4 de diciembre de 2013].

GRIFFITHS, J.G.

1980 The origins of Osiris and his cult. Leiden: Brill.

GROMBRICH E.H.

1991 The story of art. Oxford.

KAY, P. y L. MAFFI

1999 «Color appearance and the emergence and evolution of basic color lexicons». En: American Anthropologist 101.

KEES, $\mathrm{H}$.

1943 Farbensmbolik in agyptischen Religiosen Texten. Nawag 11,

LUCAS, A.

1962 Ancient Egyptian Materials and industries. London.

MANNICHE, L.

1970 «The Complexion of Queen Ahmosi Nefertere». En: Acta Orientalia 40.

MATHIEU, B.

2009 «Les couleurs dans les Textes des Pyramides : approche des systemes chromatiques». En: Egypte Nilotique et Mediterraneenne 2.

MERTZ, B.

1966 Red Land, Black Land. London: Hodder and Stoughton.

NASR, S.H.

2010 Qur'an. Encyclopaeædia Britannica [en línea]. <http://www.britannica.com/EBchecked/ topic/487666/Quran>.

PASTOUREAU, M. y D. SIMONNET

2006 Breve Historia de los Colores. Barcelona: Paidos.

PFEIFER, H. E.

1965 L'harmonie des couleurs. Paris: Dunod.

ROBINS, G.

2008 «Color symbolism». En: The oxford Encyclopedia of Ancient Egypt. Oxford: Oxford University Press. 
RODZIEWICZ, M,

1983 «Egyptian Glazed Pottery of the Eighth to Ninth Centuries». Bulletin de la Société d'Archéologie Copte 25.

RUTSCHOWSCAYA, M. H. y D. BÉNAZETH

2012 L'art Copte en Égypte : 2000 ans de christianisme: exposition présentée à l'Institut du monde arabe, Paris du 15 mai au 3 septembre 2000 et au musée de l'Éphèbe au Cap d'Agde du 30 septembre 2000 au 7 janvier 2001. Paris: Gallimard : Institut du Monde Arabe.

SAHLINS, Marshall

1977 «Colors and cultures». En: J.L.Dolgin, D.S. Kemnitzer., D.M Schneider (eds), Symbolic Anthropology: A Reader in the Study of Symbols and Meaning. New York: Columbia University press, pp. 165-180. Cf. in Semiotica 16, 1976.

SHEHATA, Ahmed y Abdel Aziz GOUDA

s.f. Quira'at fi Attazawok Alfanni wa Tarikh Alfann, El Cairo. p.120.

SONIRON, Serj

1994 Los sacerdotes en el antiguo Egipto, Trad. Eisa Tonos, Damasco.

WARBURTON, D.

2004 «The terminology of ancient egyptian colours in contexts». En: L.Cleland, K. Stears, G. Davies (eds). Colour in the ancient Mediterranean world. Oxford: Hedges. BAR International series, 1267.

WHITFIELD, Ph., N. TOMOUM y S. MAREI (editores)

2010 Coptic Art Revealed, Supreme Council of Antiquities. Exhibición en El Cairo, Palacio de Amir Taz, del 9 de diciembre de 2010 al 31 de enero de 2011. < www.copticartrevealed.com>.

\section{FigURAS}
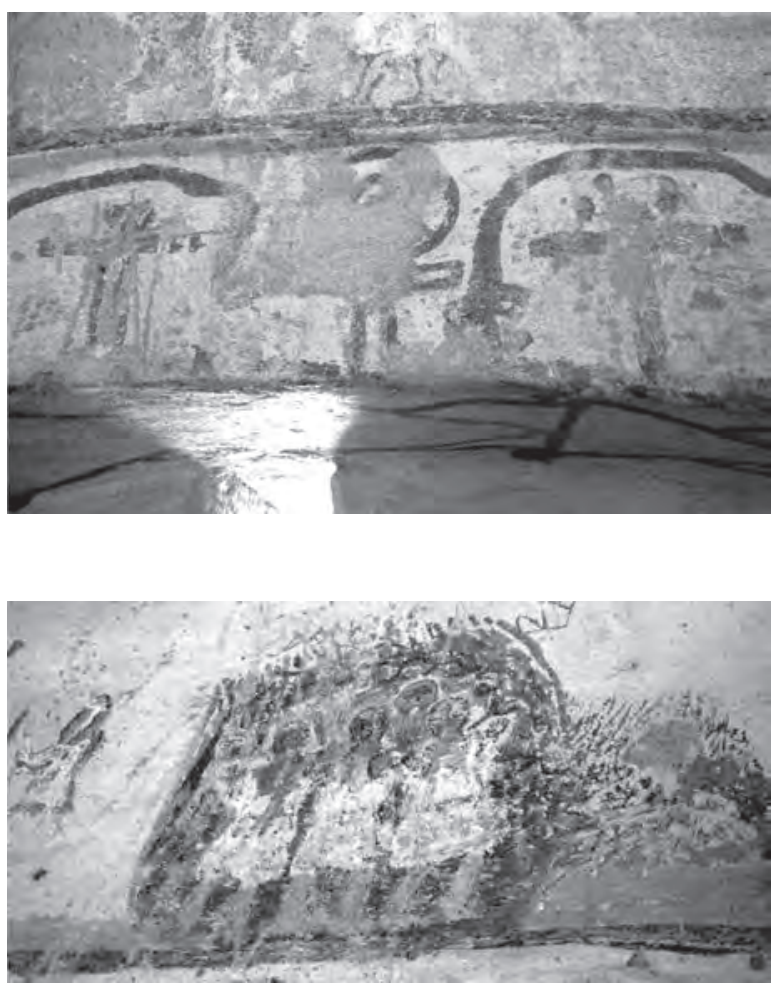

Figura 1. En esta imagen se representa a Moisés y se aprecian tres arcadas que tiene tres entradas. La del medio está formada por un arco apuntado con una puerta de tallos de madera cruzados; en el arco se ve un Ankh (la cruz). A los lados de la puerta del medio se encuentra un baldaquín de seis pilares. A la derecha hay una entrada y por encima se ve una forma piramidal; a la izquierda de la entrada se encuentran once escalones que conducen a la entrada. Las seis columnas varían en sus colores, entre el color rojo oscuro con puntos, o el amarillo con líneas negras entrecruzadas, también el rojo claro decorado con el amarillo (la construcción representa a Jerusalén).

Figura 2. Encontramos la imagen de Daniel; se representa la historia de los tres hebreos. La escena representa a tres personas en el fuego, levantando sus manos y en fila. Detrás de ellos se ve el ángel de Dios, mientras que una persona enfrente de ellos tres enciende el fuego. Encima de la imagen está escrito "el horno". Los tres hebreos llevan camisas blancas, su cuerpo es de color rojo oscuro y, el pelo $y$ los ojos son de color negro, mientras la cara del ángel es de color rojo claro, y la llama del fuego es de color rojo oscuro. 


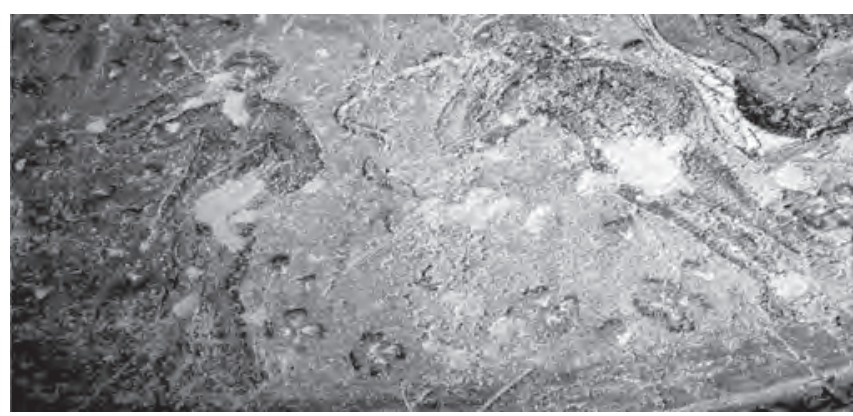

Figura 3. Adán y Eva: El artista los pintó con el color rojo rosado y también las líneas que marcan el dibujo, el cuello de Eva es más blanco que su tez, y encima de los dos se escribió Adán y Eva. Se puede leer mi artículo en línea sobre el mismo tema de los colores y su simbología en el Antiguo Egipto con citas y material leído: Qadus, Ezzat Zaki y Elsayed, Al Athar wal Fonun Alquiptía, Dar Alma'refah Aljame'ya, Alejandría, 2000, p. 210.

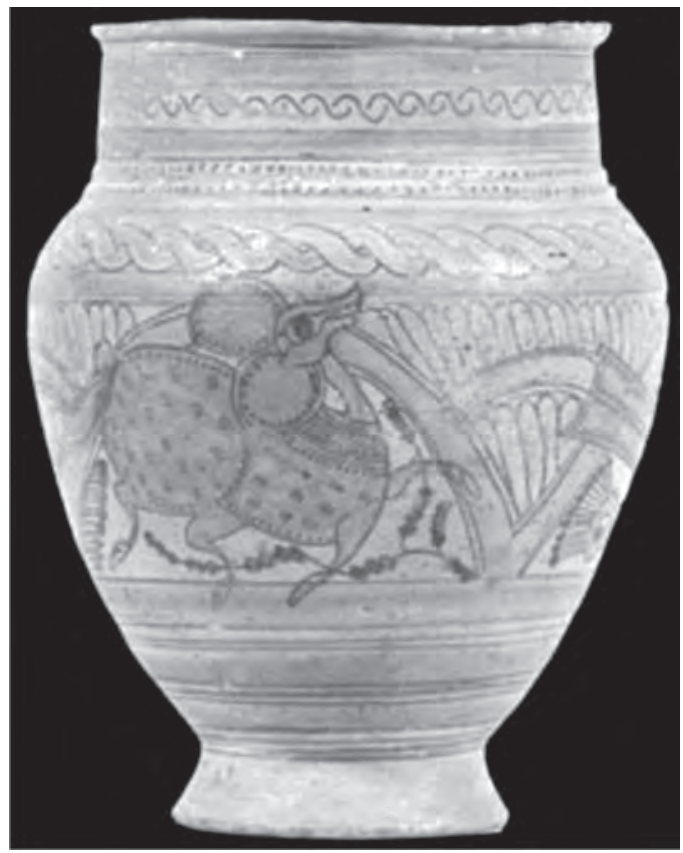

Figura 5. Un gran jarro con representaciones de color negro y rojo representando un pájaro, una liebre y otras formas geometricas.

Figura 6. Una gran jarra de barro cocido con representaciones geometricas y vegetales de colores rojo y negro del siglo VI-VII.

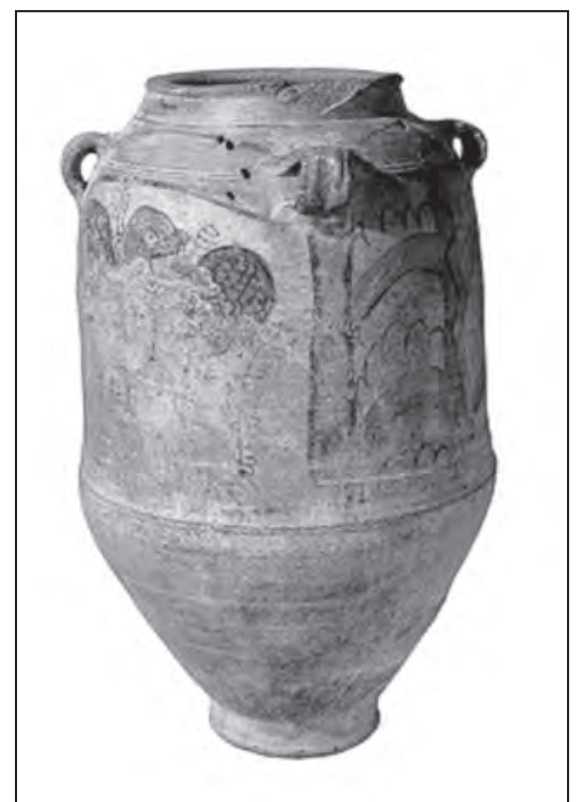

Figura 4. Una gran jarra con representaciones de colores de un pajaro extendiendo sus alas, la decoración esta en la parte superior. Esta dedicada a consrvar materias sólidas. Las representaciones estan divididas en grupos separados por columnas de color rojo con tinta negra encima. Hay lineas en zigzag parecidas al signo egipcio antiguo del agua dulce.

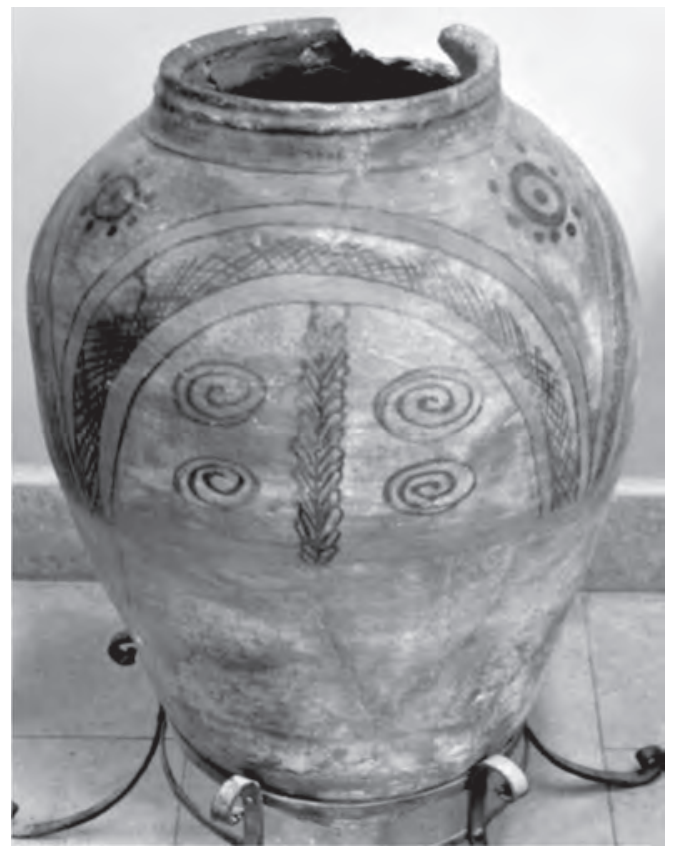




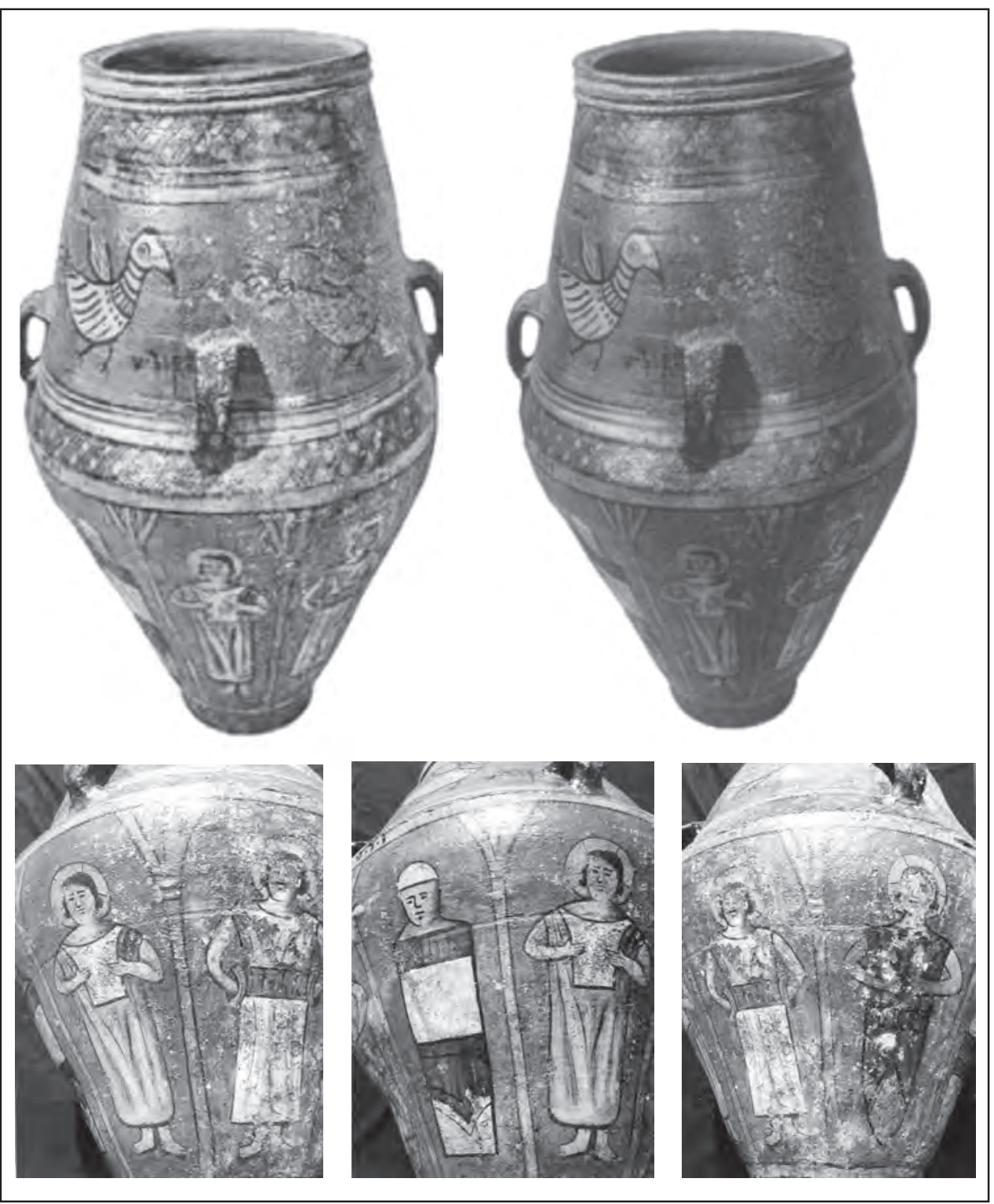

Figura 7. Pieza no. 7611, siglo VII-IX, Museo Copto. Jarra de forma cónica, donde se representa unos pájaros, un ser humano con aureola ${ }^{40}$.

40 Chevalier, Jean \& Alain Gheerbrant. A Dictionary of Symbols. Cambridge: Basil Blackwell Inc. 1994.

- Pascale Ballet. «Ceramic, Coptic». En: The Coptic Encyclopedia 2. Aziz S. Atiya, editor-in-chief. New York. 480504

- Rodziewicz, M, «Egyptian Glazed Pottery of the Eighth to Ninth Centuries,» Bulletin de la Société d'Archéologie Copte 25: 73-75. 1983.

- Burmester, O.H.E., Egyptian or Coptic Church a detailed description of her rites. El Cairo. 1967, p. 201-216. 


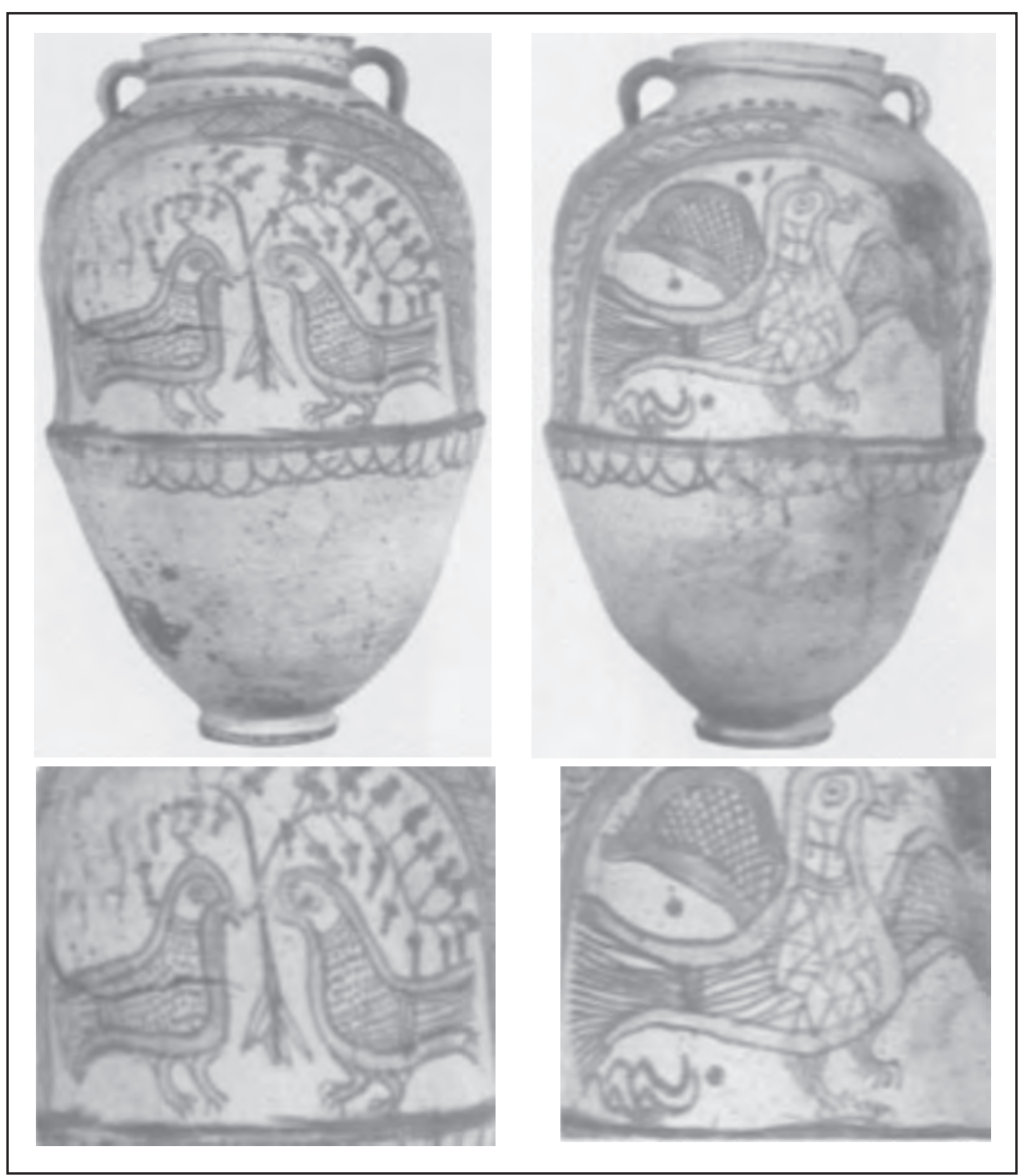

Figura 8. Pieza no. AI 2003, siglo VI, Museo de Budapest. Jarra para guardar objetos donde se ven imágenes de palomas, árboles y cruces, de color rojo con amarillo.
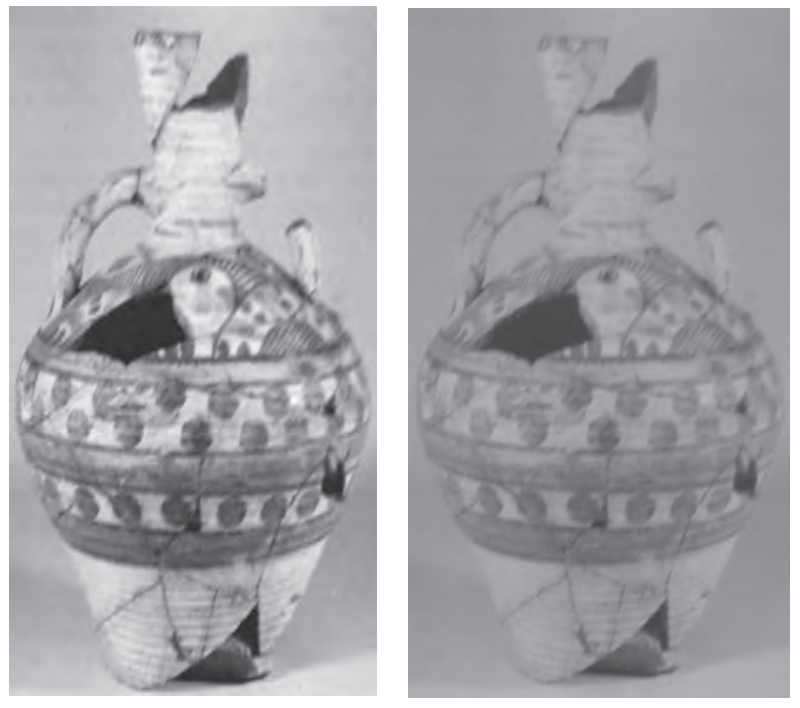

Figura 9. Pieza no. 84, siglo VI-VII, Museo Copto. Recipiente con decoraciones geométricas horizontales circulares y líneas finas y arcos de color verde. 

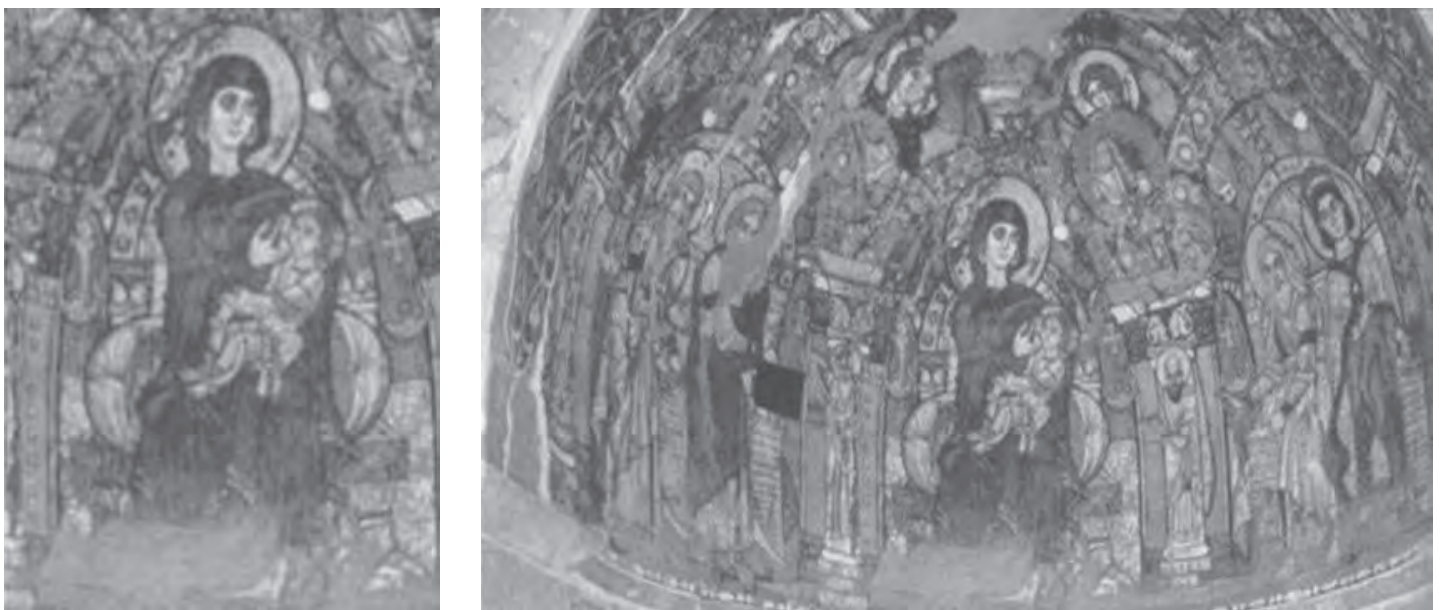

Figura 10. Un grabado del Convento Rojo, Sohag, de la Virgen con el niño, siglo VI-VIII ${ }^{41}$.

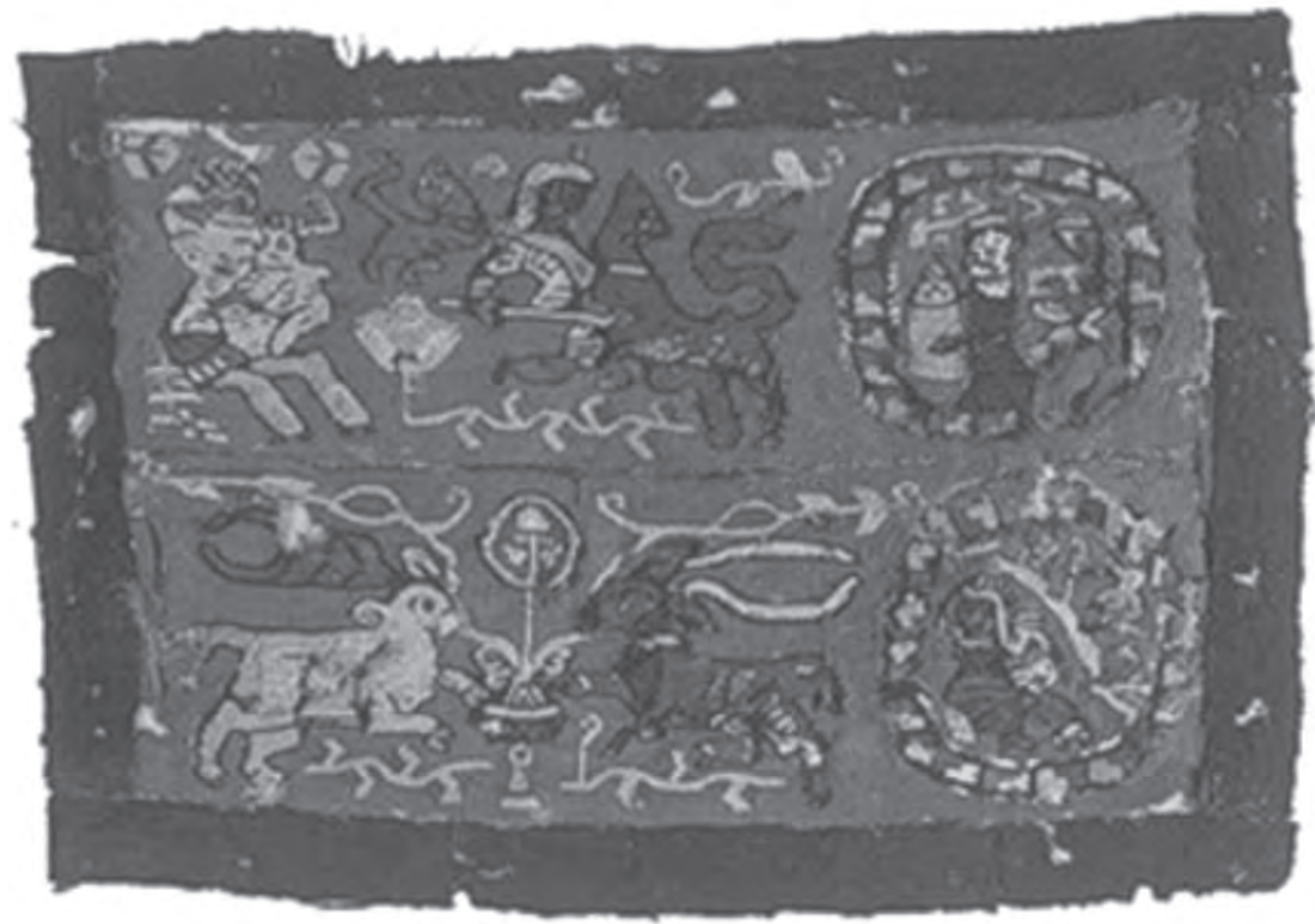

Figura 11. Un tejido rectangular de lana de color azul oscuro con decoraciones de animales y humanos.

41 Whitfield, P. et al. (ed.), Coptic Art Revealed, Supreme Council of Antiquities Exhibition, 2010, El Cairo, fig. 11. 


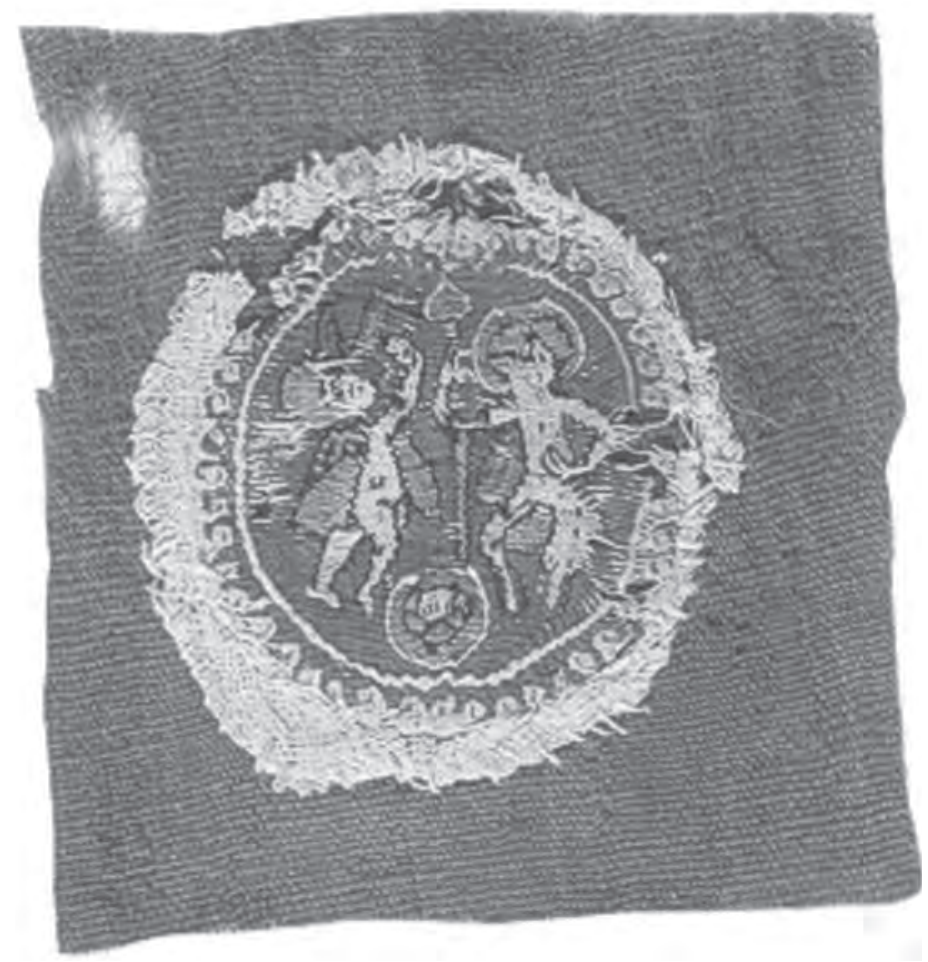

Figura 12. Una pieza de tejido copto de varios colores donde se ven dos personas, una de ellas puede ser un religioso o sacerdote.

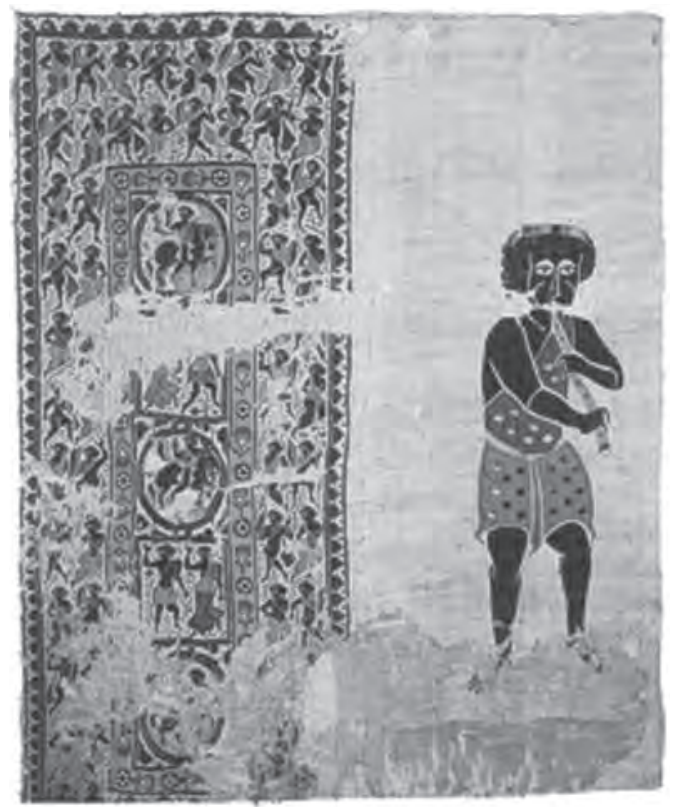

Figura 13. Una gran parte de una cortina donde se ven muchos colores y decoraciones de formas humanas, animales y geométricas. Se ve un hombre tocando la flauta. 


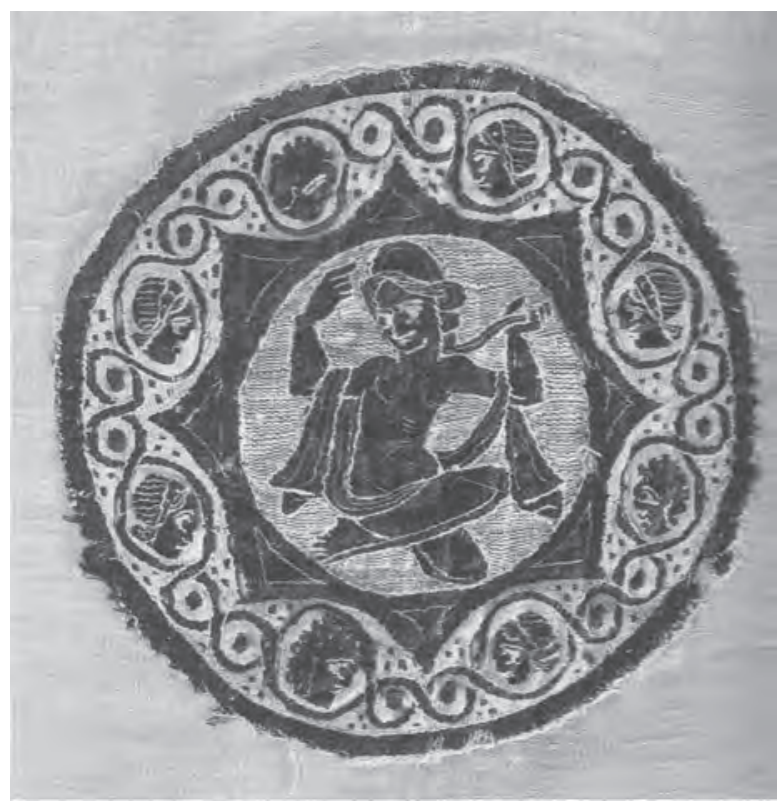

Figura 14. Tejido de lana y lino, de color natural donde se representa Afrodita, siglo IV-VI, Museo Nacional de La Edad Media, Paris. No. $22453^{42}$.

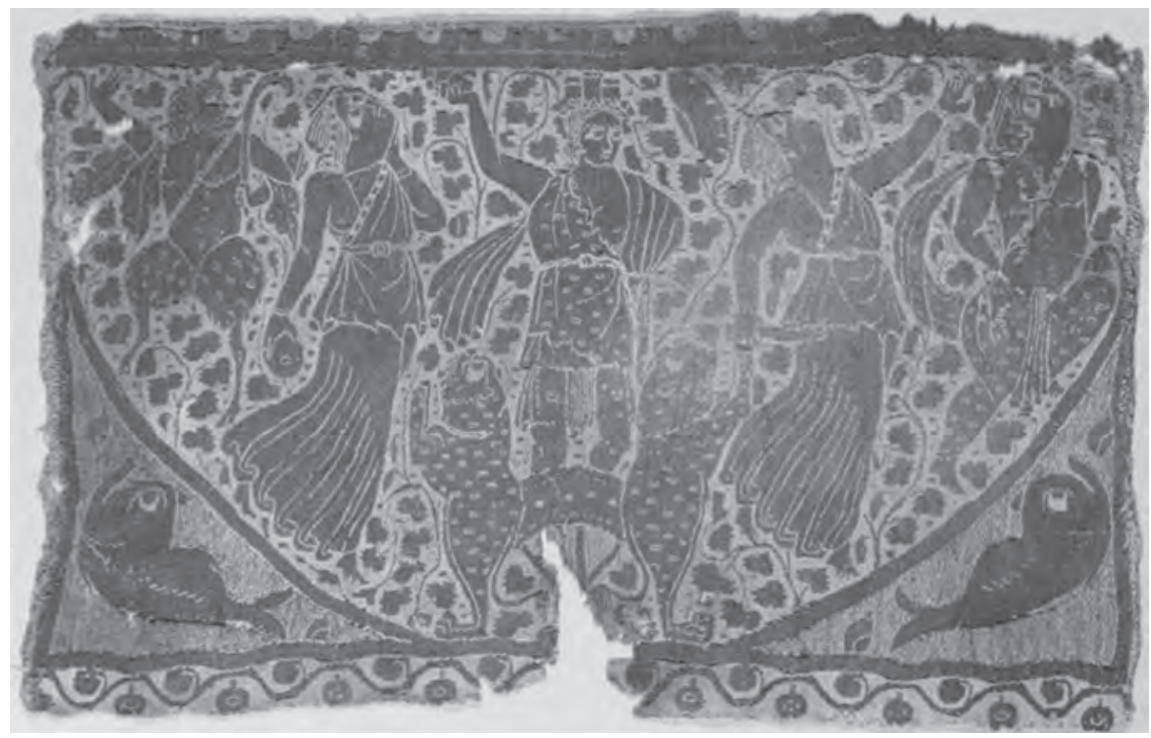

Figura 15. Tejido de Akhmim de lana, color natural bordado con lana púrpura, representando las victorias de Dionisio, siglo IV, Museo Metropolitano, Nueva York, no. 90,5,837"3.

42 À L'Institut du Monde Arabe et au Musée de L'Éphèbe au Cap d'Agde. L'Art Copte en Égypte: 2000 Ans de Christianisme. Milan: Gallimard, 2000: 162, fig.160.

43 http://www.metmuseum.org/toah/works-of (art/90.5.873\#ixzz0m XM8SUXF) 